\title{
Comparison of the effect of levofloxacin-based three-drug regimen with clarithromycin-based four-drug regimen in the treatment of Helicobacter pylori infection in Birjand
}

\author{
Fatemeh Abasnia ${ }^{(1)}$, Tahereh Fakharian ${ }^{\left(D^{2}\right.}$, Fatemeh Salmany ${ }^{\left(D^{3}\right.}$
}

\begin{abstract}
Since helicobacter pylori is a prevalent infection in Iran, it is necessary to search for an effective, low-cost, and easy diet to eradicate it. This study compares the effect of levofloxacin-based regimen along with clarithromycin-based regimen on the treatment of helicobacter pylori (H. pylori). This quasi-experimental study was performed on 161 patients with $\mathrm{H}$. pylori infection who referred to the gastrointestinal clinic of Valiasr Hospital in Birjand, Iran. The patients were randomly divided into two groups. The first group was treated with levofloxacin, pantoprazole, and amoxicillin, and the second group received amoxicillin, pantoprazole, clarithromycin, and bismuth sub citrate for 14 days. The urease breath test was performed four weeks after the end of the treatment to check the eradication of the condition. The eradication occurred in 67 $(91.8 \%)$ and $55(70.5 \%)$ patients treated with levofloxacin and clarithromycin, respectively. A p-value of 0.001 was considered statistically significant. Moreover, there was no statistically significant difference between two groups in terms of complications $(\mathrm{P}=0.3)$. The results showed that the levofloxacin-based regimen could be used as an alternative to four clarithromycin-based therapies due to its greater efficacy in eradication of $\mathrm{H}$. pylori despite the lower number of drugs and similar side effects.
\end{abstract}

Keywords: Clarithromycin, Eradication, Helicobacter pylori infection, Levofloxacin

Citation: Abasnia F, Fakharian T, Salmany F. [Comparison of the effect of levofloxacin-based three-drug regimen with clarithromycin-based four-drug regimen in the treatment of Helicobacter pylori infection in Birjand]. J Birjand Univ Med Sci. 2021; 28(2): 179-184. [Persian]

DOI http://doi.org/10.32592/JBirjandUnivMedSci.2021.28.2.108

${ }^{1}$ Student Research Committee, Birjand University of Medical Sciences, Birjand, Iran

2 Internal medicine Department, Birjand University of Medical Sciences, Birjand, Iran

3 Department of Epidemiology and Biostatistics, Faculty of Health, Birjand University of Medical Sciences, Birjand, Iran
}

Corresponding author: Internal medicine Department, Birjand University of Medical Sciences, Birjand, Iran Tel: +9856-32041100 


\section{مقايسه تأثير " رزيم سه دارويى بر پايه لووفلوكساسين" با "رزيم جهار دارويى بر هايه كلاريترومايسين" در درمان هليكوباكترييلورى در شهر بير جند}

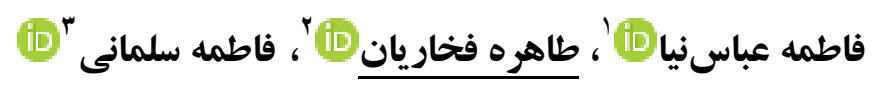

\section{جُكيده}

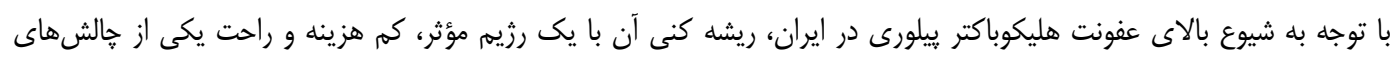

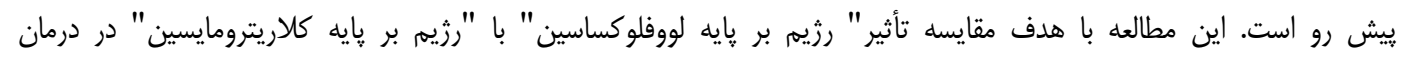

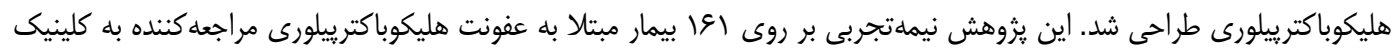

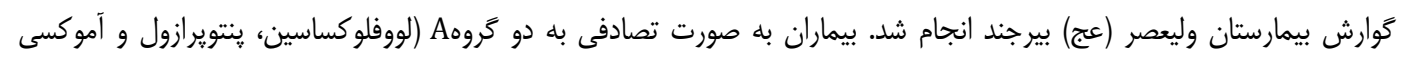

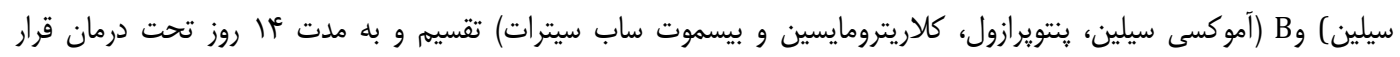

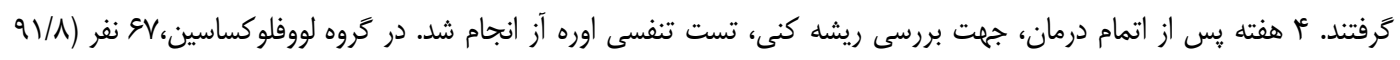

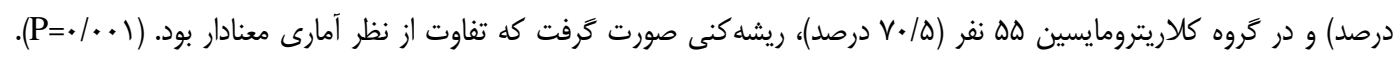

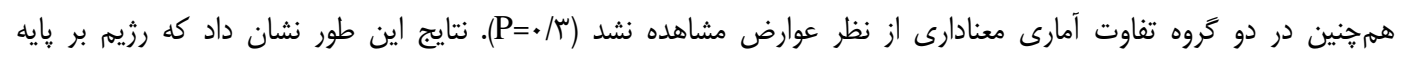

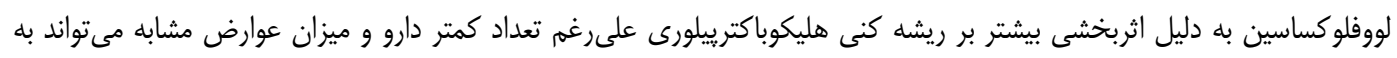

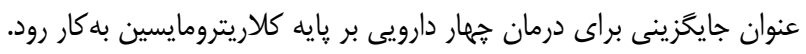

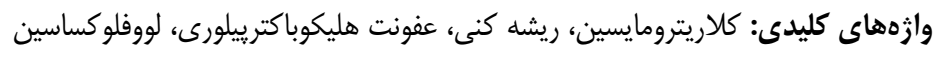

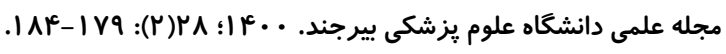

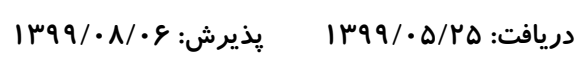

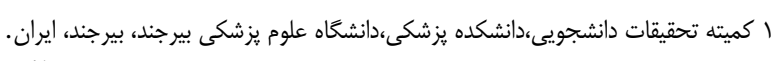

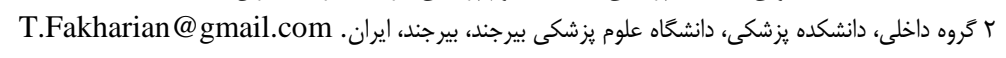

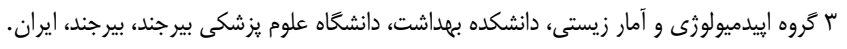

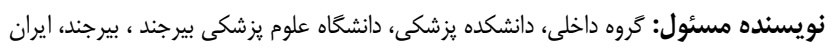

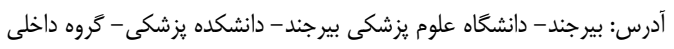

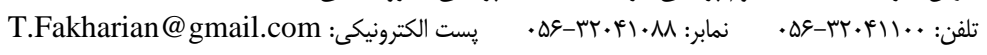


قصد داريم اثر بخشى اين دو رثيم را با توجه به تعداد كمتر دارو و مقدمه

يذيرش بهتر رزيم لووفلوكساسين مقايسه و امكان استفاده از اين رزيم بهجاى رزيم كلاريترومايسين را بررسى نماييم.

\section{روش تحقيق}

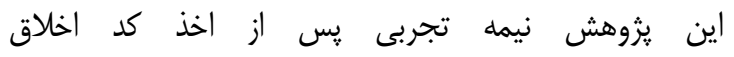
(IR.BUMS.REC.1398.182) مبتلا به عفونت هليكوباكترييلورى كه به كلينيك گوارش بيمارستان

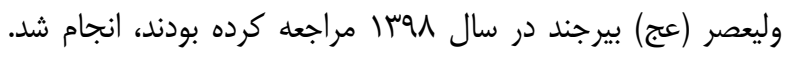
معيارهاى ورود به مطالعه شامل: ابتلا به عفونت هليكوباكترييلورى

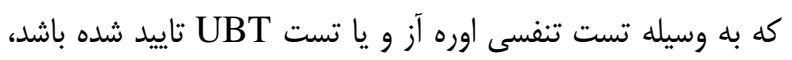
تمايل به همكارى در مطالعه، عدم استفاده از داروهاى مهاركننده

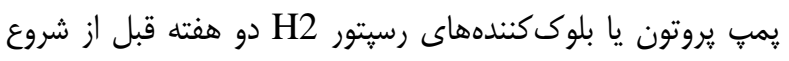

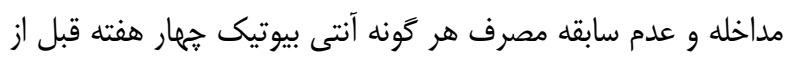
شروع مداخله تعيين كرديد. همجنين بيمارانى كه داراى سابقه درمان ملنه قبلى هليكوباكترييلورى بودند، زنان باردار، سابقه بدخيمى، سابقه جراحى كاستر كتومى، وجود بيمارى كبدى شديد يا هر بيمارى شديد

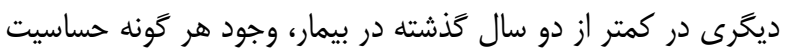

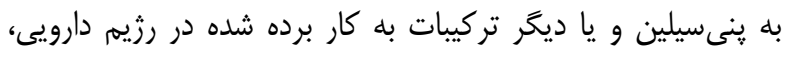

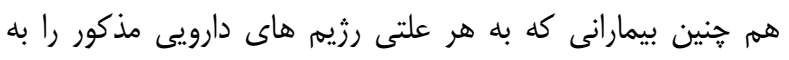
طور كامل مصرف نكردند، از مطالعه خارج شدند.

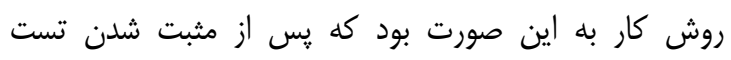

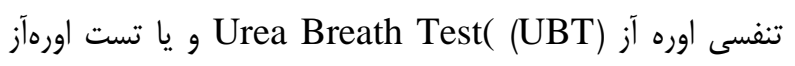
سريع، بيماران به صورت تصادفى به دو گروه A و B تقسيم شدند.

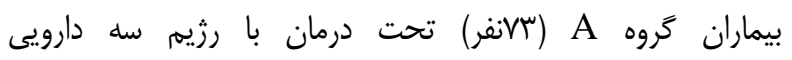

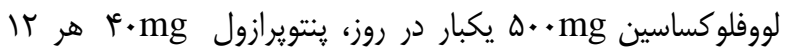

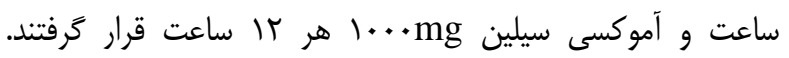

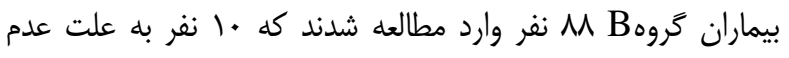

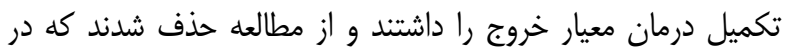

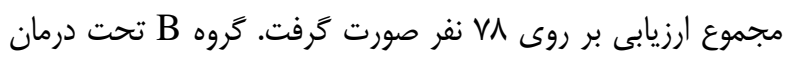

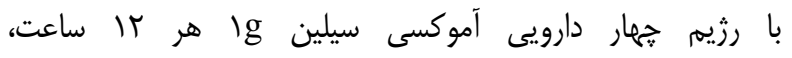

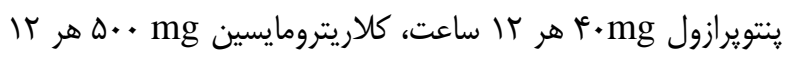

هليكوباكترييلورى يكى از شايع ترين عفونت هاى باكتريال

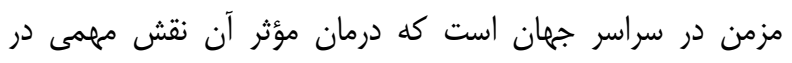

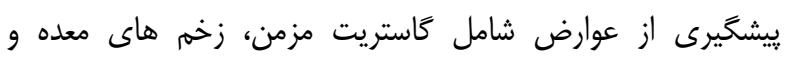
دئودنوم، لنفوم بافت لنفاوى همراه مخاط و سرطان ستان معده دارد (1).

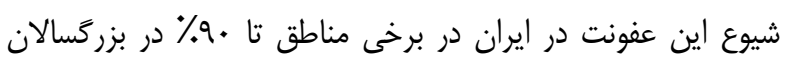
كزارش شده است (r). تاكنون رزيم هاى مختلفى جهت ريشه كنى هليكوباكتر بيلورى در كشورهاى مختلف دنيا به كار ترفته شده است. يكى از اين رزئم رئه هاى ير كاربرد در ايران رزيم سه دارويى بر بايه كلاريترومايسين

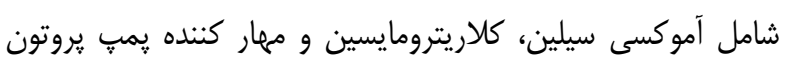

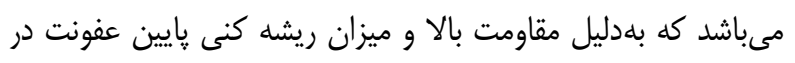
راهنماى كشورى درمان توصيه شده است در صورت استفاده، بيسموت به آن اضافه شود (َّ)

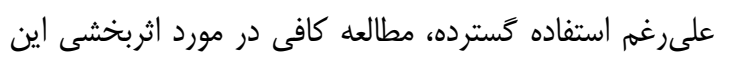

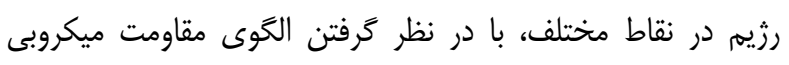

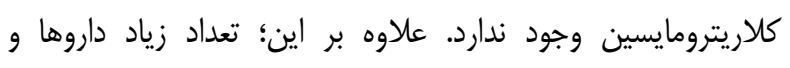

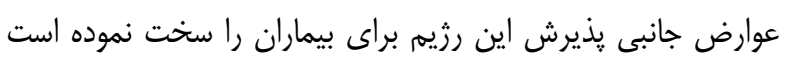

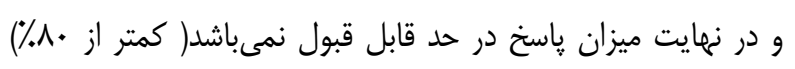

اين مهم نياز به ارزيابى رزيمهاى ديخر توصيه شده جهت

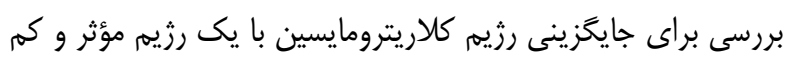

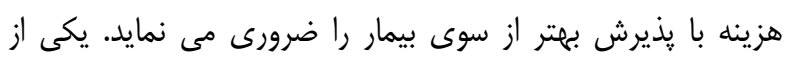

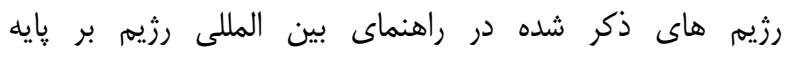

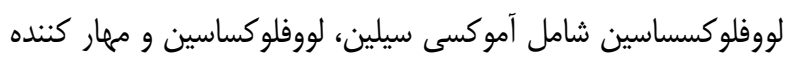
يمٍ يروتون مىباشد (ه). مطالعات متعددى در اين زمينه وجود دارد.

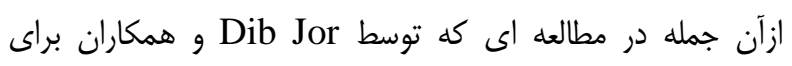

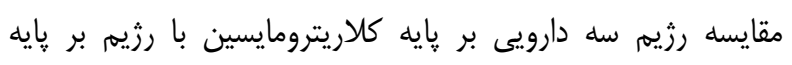

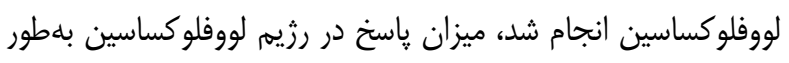

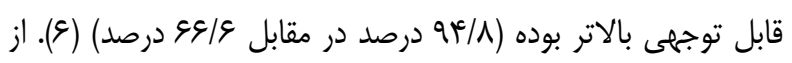
آنجا كه مطالعهاى در خصوص مقايسه اثربخشى اين رثيم با رثيم بر بر برد

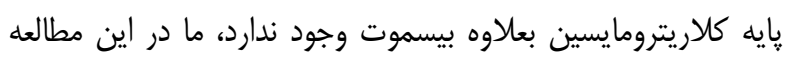


و در گروه لووفلوكساسين QV نفر (1)/ (9) درصد) بهبود يافتند

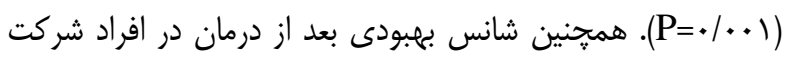

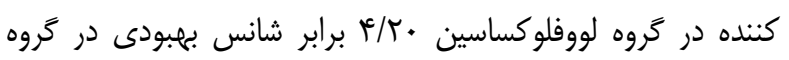

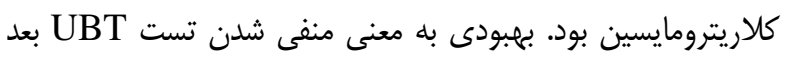

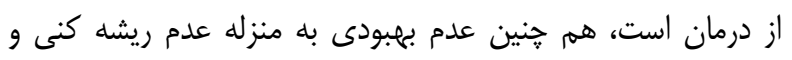

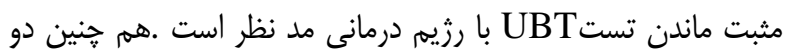

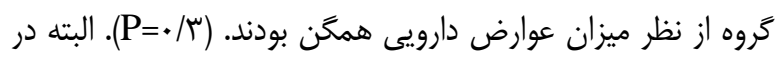

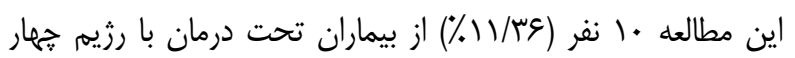
دارويى به دليل عدم يذيرش داروها و تكميل نكردن دوره درمان، از مطالعه حذف شدند. (جدول r)

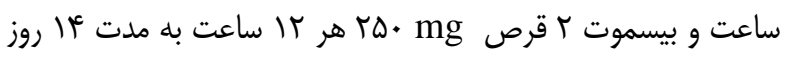

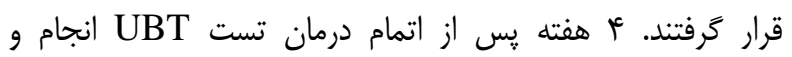
نتيجهدو گروه مقايسه شد.

\section{يافتهها}

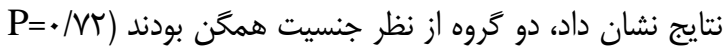

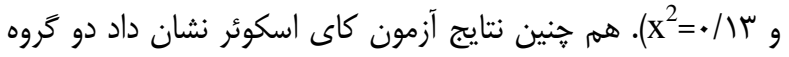

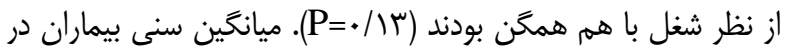

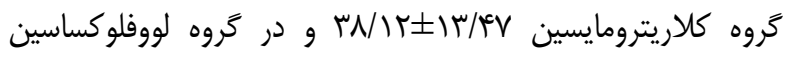

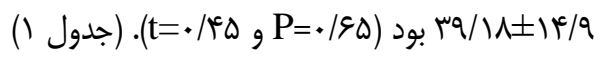
نتايج نشان داد در كروه كلاريترومايسين فه نفر (ه/. V درصد)

\begin{tabular}{|c|c|c|c|c|c|c|c|}
\hline \multirow[t]{2}{*}{ سطح معنىدارى } & \multirow[t]{2}{*}{ آماره آزمون } & \multicolumn{2}{|c|}{ تروه كلاريترومايسين } & \multicolumn{2}{|c|}{ تروه لووفلوكساسين } & \multirow{2}{*}{ ويزَّى هاى دموكَر افيكى } & \\
\hline & & درصد & تعداد & درصد & تعداد & & \\
\hline \multirow[t]{2}{*}{$\cdot / V T$} & 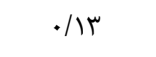 & $\Delta \mathrm{V} / \mathrm{V}$ & is & $\Delta r / \Lambda$ & r. & 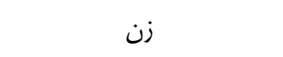 & جنس \\
\hline & & 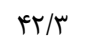 & 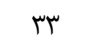 & $r \Delta / r)$ & 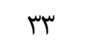 & 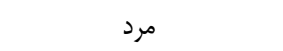 & \\
\hline \multirow[t]{4}{*}{ r } & $N / F$ & r & r & $r \cdot / l e$ & tr & ازاد ازد & 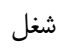 \\
\hline & & $\mathrm{FV} / \mathrm{F}$ & rv & $r / A F$ & rr & خانه دار & \\
\hline & & $11 / 0$ & 9 & $q / \Delta r$ & v & كارمند & \\
\hline & & $1 \% / r$ & 11 & $19 / 0$ & Ir & ساير & \\
\hline$\cdot 190$ & $\cdot / F \Delta$ & \multicolumn{2}{|c|}{$r N / I T \pm I r / q V$} & \multicolumn{2}{|c|}{$r q / \backslash \Lambda \pm 1 \kappa / q$} & ميانكَين (انحراف معيار) & 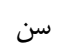 \\
\hline
\end{tabular}

جدول ז- مقايسه درصد ياسخ به درمان و ميزان شانس بهبود بعد از درمان بيماران در دو تروه كلاريترومايسين و لووفلوكساسين

\begin{tabular}{|c|c|c|c|c|c|c|c|}
\hline \multirow{2}{*}{ نسبت شانس } & \multirow[t]{2}{*}{ P-value } & \multirow[t]{2}{*}{ آماره آزمون } & \multicolumn{2}{|c|}{ بهبودى } & \multicolumn{2}{|c|}{ عدم بهبودى } & \multirow{2}{*}{ كروه درمانى } \\
\hline & & & درصد & تعداد & درصد & تعداد & \\
\hline$r / r$. & $.1 . .1$ & $1 . / 99$ & $v \cdot 10$ & $\Delta Q$ & $r q / \Delta$ & r & كلاريترومايسين \\
\hline & & & $91 / \wedge$ & qV & $N / r$ & 9 & لووفلوكساسين \\
\hline
\end{tabular}

بهبودى: به منزله منفى شدن تست اوره از بعد از درمان است.

بالاى هم درصد مشخص مى شود (V)، بنابراين مىتوان كفت رزيم درمانى سه دارويى لووفلوكساسين موفق عمل كرده است. اين يافته مانه بر اساس يافتههاى اين مطالعه، ميزان ريشه كنى با رزيم

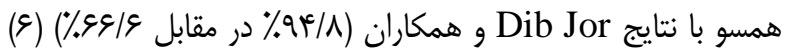

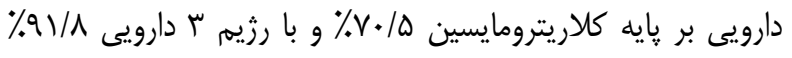

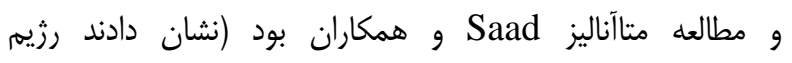

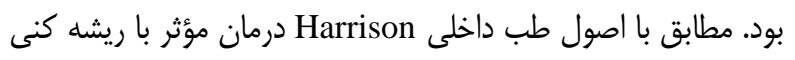




\section{نتيجه تيرى}

نتايج مطالعلى حاضر حاكى از اثربخشى بهتر رزيم بر يايه لووفلوكساسين نسبت به كلاريترومايسين مىباشد. بنابراين مىتوان كفت درمان با لووفلوكساسين مىتواند با توجه به اثربخشى بهتر،

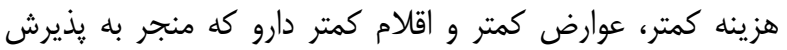
بهتر بيمار مى گردد به عنوان درمان جايكزين رزيم أ دارويى بر بايه كلاريترومايسين استفاده شود.

\section{تقدير و تشكّر}

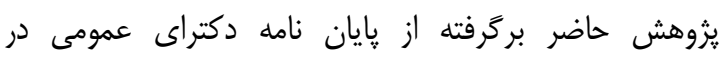

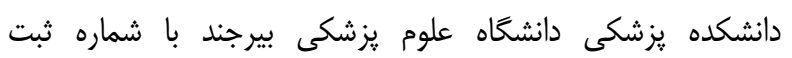

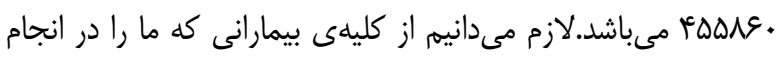
اين طرح يارى نمودند و همجنين پاييگاه تحقيقات بالينى بيمارستان

$$
\text { ولى عصر (عج) صميمانه قدردانى كنيم. }
$$

تضاد منافع

نويسندًان مقاله اعلام مىدارند كه هيج گَونه تضاد منافعى در

$$
\text { يزوهش حاضر وجود ندارد. }
$$

لووفلوكساسين بهطور معنادارى مؤثرتر از رزيم جهار دارويى بر קِايه تتراسايكلين بوده و بهتر تحمل مى شود (^). مطالعه ى Nissta و همكاران نيز نشان داد بهترين رزيه، رزيم سه دارويى بر קاياهى

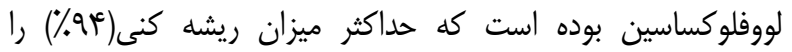
داشته است (9). افزودن بيسموت به رزيم سه دارويى آموكسىسيلين، اميرازول و كلاريترومايسين باعث شده تعداد داروهاى مصرفى روزانه

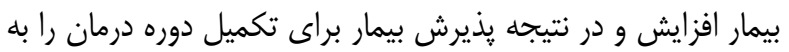

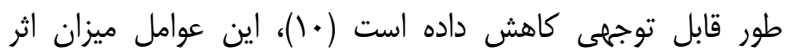

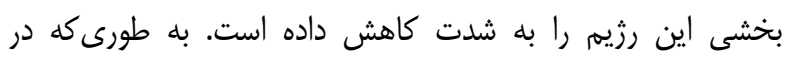

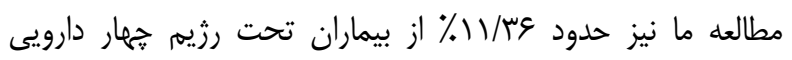
بلددليل عدم يذيرش داروها و تكميل نكردن دوره درمان، ريزش

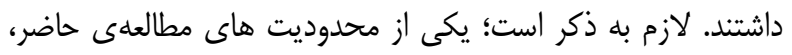

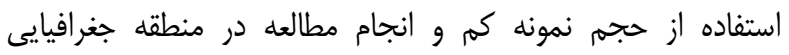

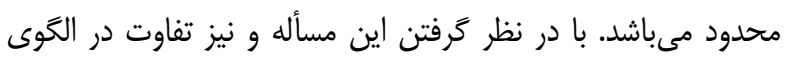
مقاومت در مناطق مختلف ممكن است نتايج قابل تعميم به ساير

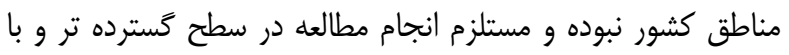
حجم بالاتر در ديخر مناطق جغرافيايى ايران باشد.

1- Uemura N, Okamoto, Yamamoto S, Matsumura N, Yamaguchi S, Yamakido M, et al. Helicobacter Pylori Infection and the Development of Gastric Cancer. N Engl J Med. 2001; 345(11): 784-9. DOI: 10.1056/NEJMoa001999

2- Fakheri H, Bari Z, Aarabi M, Malekzadeh R. Helicobacter pylori eradication in West Asia: a review. World J Gastroenterol. 2014; 20(30): 10355-10367. DOI: 10.3748/wjg.v20.i30.10355

3- Yu L, Luo L, Long X, Liang X, Ji Y, Graham DY, et al. High-dose PPI-amoxicillin dual therapy with or without bismuth for first-line Helicobacter pylori therapy: A randomized trial. Helicobacter. 2019; 24(4): e12596. DOI: 10.1111/hel.12596

4- Mohammadi M, Doroud D, Mohajerani N, Massarrat S. Helicobacter pylori antibiotic resistance in Iran. World J Gastroenterol: WJG. 2005; 11(38): 6009-13. DOI: 10.3748/wjg.v11.i38.6009

5- Chey WD, Leontiadis GI, Howden CW, Moss SF. ACG clinical guideline: treatment of Helicobacter pylori infection. Am J Gastroenterol. 2017; 112(2): 212-39. DOI: 10.1038/ajg.2016.563

6- Dib J, Jr., Alvarez B, Mendez L, Cruz ME. Efficacy of PPI, levofloxacin and amoxicillin in the eradication of Helicobacter pylori compared to conventional triple therapy at a Venezuelan hospital. Arab J Gastroenterol. 2013; 14(3): 123-5. DOI: 10.1016/j.ajg.2013.09.001

7- Jameson JL. Harrison's principles of internal medicine. 20 ${ }^{\text {th }}$ edition. New York: McGraw Hill Education, 2018. 
8- Saad RJ, Schoenfeld P, Kim HM, Chey WD. Levofloxacin-Based Triple Therapy versus Bismuth-Based Quadruple Therapy for Persistent Helicobacter pylori Infection: A Meta-Analysis: CME.Am J Gastroenterol. 2006; 101(3): 488-96. DOI: 10.1111/j.1572-0241.2006.00637.x.

9- Nista EC, Candelli M, Cremonini F, Cazzato IA, Di Caro S, Gabrielli M, et al. Levofloxacin- based triple therapy vs. quadruple therapy in second- line Helicobacter pylori treatment: a randomized trial. Aliment Pharmacol Ther 2003; 18(6): 627-33. DOI: 10.1046/j.1365-2036.2003.01676.x

10- Bakhshi S, Ghazvini K, Beheshti A, Ahadi M, Sheykhi M. Review of antibiotic resistance of Helicobacter pylori in Iran and the world. medical journal of mashhad university of medical sciences. 2017; 60(4): 648-61. [Persian] DOI: 10.22038/mjms.2017.10191 